\title{
Photovoltaic Response of Natural Kesterite Crystals
}

\author{
Brandon Durant and B. A. Parkinson \\ Department of Chemistry and School of Energy Resources \\ University of Wyoming \\ Laramie, WY 82071 \\ Phone: 307-766-9891 \\ Email: bparkin1@uwyo.edu \\ Fax: 307-766-2807
}

\begin{abstract}
The photoelectrochemical performance of naturally occurring single and multicrystalline Kesterite or $\mathrm{Cu}_{2}(\mathrm{Zn}, \mathrm{Fe}) \mathrm{SnS}_{4}$ (CZTS) is presented. Elemental analyses of the crystals indicate high sulfur to metal atomic ratios and the presence of 12.3-14.5 atomic percent of iron presumably in the 2+ metal site replacing zinc in the lattice. Raman spectroscopy indicates the possible presence of a $\mathrm{Cu}_{2} \mathrm{SnS}_{3}$ impurity phase. Photocurrent spectroscopy measurements give a bandgap of 1.61-1.63 eV, higher than most reported values for pure $\mathrm{Cu}_{2} \mathrm{ZnSnS}_{4}$ films. Mott-Schottky measurements show that these crystals have a high doping density of about $10^{19} \mathrm{~cm}^{-3}$, that reduces to about $10^{17} \mathrm{~cm}^{-3}$ after a brief etch in $10 \% \mathrm{KCN}$ (aq.) solution. Although still low, the carrier diffusion length is increased by the removal of surface defects. This work demonstrates the ability to simply and easily evaluate the photovoltaic potential for a plethora of naturally occurring semiconducting materials.
\end{abstract}




\section{$\underline{\text { Introduction }}$}

Thin film solar cells are already making a contribution to solar electricity generation however the two favored commercial technologies, copper indium gallium diselenide (Culn $\mathrm{Ga}_{1-\mathrm{x}} \mathrm{Se}_{2}$ or $\mathrm{CIGS}$ )[1] and cadmium telluride (CdTe)[2] have issues for very large scale implementation of both the abundance (In, $\mathrm{Te})$ and the toxicity ( $\mathrm{Cd}, \mathrm{Te})$ of some constituent elements. Therefore semiconductors with the appropriate band gap and consisting of earth abundant materials, such as copper zinc tin sulfide or selenide (CZTSSe, $\mathrm{Cu}_{2} \mathrm{ZnSnSe}_{x} \mathrm{~S}_{4-\mathrm{x}}$ ) or Kesterite have been the subject of increasing research and development [3-5]. Recently laboratory cells have reached up to $12.6 \%$ conversion efficiency from just 5.45\% in 2005.[6][7] Both CIGS and CdTe are considered defect tolerant of forgiving materials since it is relatively easy to prepare $5-10 \%$ efficient solar cells from these materials using a variety of deposition techniques, whereas for other II-VI and related I-III- $\mathrm{V}_{2}$ as well as earth abundant materials such as pyrite $\left(\mathrm{FeS}_{2}\right)$, solar cells of even $5 \%$ efficiency are difficult to fabricate at least partly due to native defects. Therefore it is somewhat surprising that CZTSSe appears to be somewhat defect tolerant despite being a quaternary compound with many possible vacancy and antisite defects.

Structural, vibrational, photoluminescence, and some electronic structure studies[8-22] have been reported for single crystal CZTS, CZTSe, and CZTSSe. Photoelectrochemical photocurrent measurements on single crystals have not been reported for Kesterite despite evidence for a direct correlation with completed device short circuit currents $\left(\mathrm{J}_{\mathrm{sc}}\right)$ and overall photoconversion efficiency.[23]

Natural crystals have shown their usefulness in photoelectrochemical studies.[24-27] Well crystallized CZTS occurs in nature as the mineral Kesterite that can be found up to dimensions of $1 \mathrm{~cm}$ or larger. Therefore we thought it would be interesting to examine the photovoltaic response of some natural Kesterite crystals and investigate their impurity levels to perhaps gain some insight into the performance of CZTS thin films. Surprisingly, single crystals of some chalcogenide absorber materials such as CdTe[28] and CIS[29] show disappointingly low photocurrents compared to thin film devices due to enhanced minority carrier collection at grain boundaries in polycrystalline films.[30][31] Although this compassion has not been extensively done for CZTSSe, similar phenomena might be expected.

\section{Experimental}

A natural Kesterite crystal was obtained from a well-known deposit in the Xue Bing Mountains in the Sichuan Province in China. The large crystal was cut into smaller pieces. Kesterite from this locality are often coated with a blue-green film of the mineral Mushistonite $\left((\mathrm{Cu}, \mathrm{Zn}, \mathrm{Fe})^{2+}\left(\mathrm{Sn}(\mathrm{OH})_{6}\right)\right)$ that was removed by immersing them in concentrated $\mathrm{HCl}$ (Fisher Sci. Fair Lawn, NJ). Kesterite pieces were then cut using a slow speed diamond saw (MTI Corp., Richmond, CA) from larger pieces of the natural crystal and faces with a (110) orientation were easily cleaved with a razorblade with 9.5 and $17 \mathrm{~mm}^{2}$ active surface areas. Other crystals with similar elemental composition and sizes were also etched in a $10 \% \mathrm{wt}$ $\mathrm{KCN}$ aqueous solution. These 2-4 mm thick crystal slabs were mounted onto copper disks with conductive In/Ga paste for ohmic contact and potted in epoxy (Epoxy Patch) to insulate the metallic substrate from electrolyte solutions. The smaller sample is referred to as the Small Kesterite (SK) and 
the larger as the Large Kesterite (LK). The pieces had a DC resistance, measured using a multimeter, on the order of several $k \Omega s$ to the back contact.

Raman spectra were collected by an IM-52 spectrometer (Snowy Range Instruments) with a $532 \mathrm{~nm}$ laser excitation source. Elemental analysis was performed by energy dispersive X-Ray spectroscopy using a scanning electron microscope (FEI Quanta 450 FEG) with pure metal standards. Photoelectrochemical measurements were performed with in-house fabricated electrochemical cells with $10 \mathrm{mM}$ cobalticinium hexafluorphosphate (Strem Chemicals, Newburyport, MA) and 100mM tetrabutylammonium hexafluorphosphate $\left(E^{0}=-.755 \mathrm{~V}\right.$ vs $\mathrm{Ag}$ wire) (Sigma Aldrich, St. Louis, $\mathrm{MO}$ ) as redox couple and electrolyte respectively in acetonitrile (Fisher Sci.). Acetonitrile was chosen over water to provide a broader potential window for electrochemical measurements and for a reduced likelihood of corrosion. Platinum and silver wires were used as counter and pseudo-reference electrodes, respectively. Transient photocurrent and Mott-Schottky measurements were performed with an Ivium CompactStat potentiostat with photocurrent interrupted by hand chopping a $40 \mathrm{~mW}$ (as measured by power meter through cell with electrolyte) $532 \mathrm{~nm}$ laser.

Incident Photon to Current Efficiency (IPCE) spectra were collected at $2 \mathrm{~nm}$ intervals with $100 \mathrm{~W}$ Oriel tungsten lamp, computer controlled monochromater, Stanford Research Systems model SR830 DSP lock-in amplifier, $450 \mathrm{~nm}$ cutoff filter and in-house software utilizing a thermopile and ThorLab Cseries photodiode detector to measure the photon flux. The applied potential for IPCE and chronoamperometric measurements was $-0.5 \mathrm{~V}$ vs $\mathrm{Ag}$ wire.

\section{$\underline{\text { Results and Discussion }}$}

Figure 1 shows an optical microscopic image of the Large Kesterite (LK-21.8 mm² exposed area) and Figures $2 a$ and $2 b$ show scanning electron microscopy (SEM) images for the Large Kesterite and Small Kesterite (SK-6.3 $\mathrm{mm}^{2}$ ) pieces obtained from cutting the larger mineral crystal with a diamond saw. Using a razor blade to score the crystals, both pieces exposed smooth cleavage faces from the larger crystal. The larger sample was polycrystalline with smooth faces and smaller crystal grains while the small sample showed 2 smooth exposed faces. Five areas of the LK and 3 areas for the SK samples were investigated using EDX to obtain the elemental composition. Elemental analysis shown in Table 1 reveals that the crystal is rather sulfur rich, with a $\mathrm{S} /$ metal atm\% ratio greater than one for all areas except the third area on the SK. Both crystals showed a 12.3-14.5\% Fe that is probably occupying a 2+ metal site replacing $\mathrm{Zn}$ as is expected for the natural mineral from this locale.[32] The SK sample shows a lower $\mathrm{Fe} / \mathrm{Zn}$ ratio. After exposing a crystal to an aqueous $10 \%$ wt KCN solution for 90 seconds, the stoichiometry was similar to the LK and SK samples indicating there wasn't a change in the bulk composition which is expected from a short etching procedure.

Raman spectra (Figure 3) confirmed presence of the Kesterite phase with peaks at 338-341 and 288-291

$\mathrm{cm}^{-1}$ matching those of synthetic CZTS single crystals. Peaks at $355 \mathrm{~cm}^{-1}$ were present in both the Large and Small Kesterite pieces that have been associated with the monoclinic $\mathrm{Cu}_{2} \mathrm{SnS}_{3}$ (CTS) phase, an unwanted impurity in CZTS thin films since it lowers the power conversion efficiencies of finished devices. The CTS phase also has a vibrational mode at $290 \mathrm{~cm}^{-1}$ that is coincident with a CZTS peak. No 
distinct Raman peaks from ZnS were evident, but this phase not distinguishable in Raman spectra with $532 \mathrm{~nm}$ excitation. Recent reports discuss the difficulty of quantitative analysis of these common secondary phases, but any detection indicates a relatively high presence.[33]

Figure 4 show chopped light voltammetry measured by illuminating 5 different areas of the LK and one area after etching with a $10 \%$ wt KCN (aq.) solution for 90 seconds. The SK sample showed similar photocurrents as the LK sample. Both samples showed p-type behavior with high anodic dark currents in the positive potential range (forward bias) and some cathodic photocurrents at more negative potentials (reverse bias). The photocurrent onset was approximately $+0.1 \mathrm{~V}$ vs a $\mathrm{Ag}$ wire and the photocurrent increased with more negative applied potentials associated with increased band bending and thicker space charge layer at semiconductor/electrolyte junction allowing for more efficient extraction of minority carriers (electrons in the case of $\mathrm{p}$-type materials). Residual dark currents are possibly due to the reduction of dissolved $\mathrm{O}_{2}$ in the acetonitrile or some corrosion of the Kesterite.

Chronoamperometry with $40 \mathrm{~mW} 532 \mathrm{~nm}$ laser illumination at $-0.5 \mathrm{~V}$ vs a $\mathrm{Ag}$ wire showed photocurrents of 40 and $50 \mathrm{nA}$ for the LK and SK samples respectively, indicating that the quantum efficiencies are quite low. High photocurrent yields are not expected due to the presence of Fe in the material as well as the $\mathrm{Cu}_{2} \mathrm{SnS}_{3}$ impurity phase where both have been shown to degrade efficiencies.[34][35] The slow rise and fall of the cathodic photocurrent current is probably related to the high series resistance and resulting large RC time constant. The higher photocurrents in the SK sample could be attributed to the lower Fe content than the LK sample.

The KCN solution is a commonly used etching procedure and shows greatly enhanced photocurrents from the 10 's nA to over $1 \mu \mathrm{A}$. It has been known that KCN etching removes CuxS/Se secondary phases [36-39] of CIGSSe and CZTSSe thin films by preferentially removing $\mathrm{Cu}$, chalcogens, and also to a lesser extent Sn [40][41]. Because the short etching time only affects the surface composition of the absorber layers and not the bulk composition, most have concluded that it beneficially lowers the surface defect density of the CZTSSe/CdS interface. In our study, we are able to photoelectrochemically investigate the Kesterite/electrolyte interface without the need for CdS deposition to fabricate a solid state device. Therefore the photocurrent enhancement is likely due to improvement in near surface carrier collection efficiency and lowering of surface defect density and trap states that would lower the surface recombination rate.

The spectral response of the SK sample and post KCN sample were measured in the same electrolyte and electrochemical cell with the monochromatic light illuminating the entire exposed crystal surface. As seen in Figure 5, a clear rise in the incident photon current efficiency (IPCE) was observed around 775 $\mathrm{nm}(1.6 \mathrm{eV})$. Nonzero photocurrents at longer wavelengths were also measured. This sub-bandgap response or band tailing is usually attributed to lattice disorder or impurities with states in the band gap.[42] There is evidence that the crystal also showed multiple band gaps by the increase in IPCE at wavelengths below $600 \mathrm{~nm}$. Figure 6 shows the direct band gap estimated by plotting [IPCE/(1IPCE)*hv] ${ }^{2}$.[43] The linear region $x$-axis intercept was $1.61 \mathrm{eV}$ for the SK piece $(A)$ and $1.63 \mathrm{eV}$ for the post $K C N$ piece (B), a value higher than most reported CZTS films perhaps due to the incorporation of $\mathrm{Fe}$ into the Kesterite structure. Pure stoichiometric CZTS has been reported to have a band gap around 1.5 
eV.[44] Etching in KCN solution produces a less noisy IPCE spectrum with higher quantum yields and slightly increased the bandgap to $1.63 \mathrm{eV}$.

Mott-Schottky analysis (Figure 7) of a pre etched crystal showed a negative slope that was characteristic of p-type material indicating carrier concentrations of 7.6-7.8 $\times 10^{18} \mathrm{~cm}^{-3}$. The carrier concentration for the LK and SK samples were $1.6 \times 10^{19}$ and $8.5 \times 10^{19} \mathrm{~cm}^{-3}$ respectively (not shown). The AC series resistance was 5-7 $\mathrm{k} \Omega$, in agreement with the DC measurements of the mounted crystals. The high doping density results in very shallow $(<8 \mathrm{~nm})$ calculated space charge layer thickness. Even a high absorption coefficient at $532 \mathrm{~nm}\left(3.0 \times 10^{5} \mathrm{~cm}^{-1}\right)$ [45] results in an absorption depth of $33 \mathrm{~nm}$ partially explaining the low collection of minority carriers at most visible wavelengths. Carrier diffusion lengths are also expected to be low due to defects and impurities.

Etching with a KCN solution also influenced the Mott-Schottky results for the natural Kesterite mineral. Prior to etching, the slope of the Mott-Schottky plot was shallow (higher doping density) and the x-axis intercept (associated with the flat band potential) was highly positive. After etching, the slope was steeper associated with a lower effective doping density $\left(\sim 10^{17} \mathrm{~cm}^{-3}\right)$. The lower doping density results in a thicker space charge layer thickness, and collection of more carriers by the electron scavenger in solution. Additionally the intercept was a more physically reasonable $+0.5 \mathrm{~V}$ vs Ag wire, much closer to the photocurrent onset potential noticeable around $+0.35 \mathrm{~V}$.

\section{Conclusion}

Although two single crystal Kesterite samples both showed low photocurrent yields they allowed the measurement of their spectral response indicating a bandgap of $1.61 \mathrm{eV}$, slightly larger than the $1.5 \mathrm{eV}$ reported for pure $\mathrm{Cu}_{2} \mathrm{ZnSnS}_{4}$.[44] The large amount of Fe impurities (12.3-14.5\% presumably in the 2+ cationic site) as well as possible $\mathrm{Cu}_{2} \mathrm{SnS}_{3}$ phases results in very low photocurrent yields. However, etching the surface in $10 \%$ wt KCN (aq.) improves the photocurrent yields, presumably by removing many surface defects and producing a thicker space charge layer. The large number of semiconducting natural minerals provides an opportunity to take advantage of the naturally provided crystals to assess the photovoltaic potential of these many compounds.

\section{Acknowledgements}

The authors would like to thank Dr. Susan Swapp and Dr. Norbert G. Swoboda-Colberg for their assistance and training with the Scanning Electron Microscope, as well as Prof. Brian Leonard for the use of his Raman instrumentation and Dr. Katarzyna Skorupska for useful experimental assistance and helpful discussions. BD acknowledges the support of a Graduate Research Fellowship from the School of Energy Resources at the University of Wyoming. 


\section{$\underline{\text { References }}$}

[1] P. Jackson, D. Hariskos, E. Lotter, S. Paetel, R. Wuerz, R. Menner, et al., New world record efficiency for Cu(In,Ga)Se2 thin-film solar cells beyond 20\%, Prog. Photovolt: Res. Appl. 19 (2011) 894-897. http://dx.doi.org/10.1002/pip.1078.

[2] X. Wu, High-efficiency polycrystalline CdTe thin-film solar cells, Solar Energy. 77 (2004) 803-814. http://dx.doi.org/10.1016/j.solener.2004.06.006

[3] H. Katagiri, K. Jimbo, W.S. Maw, K. Oishi, M. Yamazaki, H. Araki, et al., Development of CZTS-based thin film solar cells, Thin Solid Films. 517 (2009) 2455-2460. http://dx.doi.org/10.1016/j.tsf.2008.11.002.

[4] V.A. Akhavan, B.W. Goodfellow, M.G. Panthani, C. Steinhagen, T.B. Harvey, C.J. Stolle, et al., Colloidal CIGS and CZTS nanocrystals: A precursor route to printed photovoltaics, Journal Of Solid State Chemistry. 189 (2012) 2 - 12. http://dx.doi.org/10.1016/j.jssc.2011.11.002.

[5] S. M. Suryawanshi, G.L. Agawane, S.M. Bhosale, S.W. Shin, P.S. Patil, et al., CZTS based thin film solar cells: a status review, Materials Technology. 28 (2013) 98-109.

http://dx.doi.org/10.1179/1753555712Y.0000000038.

[6] H. Katagiri, Cu2ZnSnS4 thin film solar cells, Thin Solid Films. 480-481 (2005) 426-432.

http://dx.doi.org/10.1016/j.tsf.2004.11.024.

[7] W. Wang, M.T. Winkler, O. Gunawan, T. Gokmen, T.K. Todorov, Y. Zhu, et al., Device Characteristics of CZTSSe Thin-Film Solar Cells with 12.6\% Efficiency, Adv. Energy Mater. 4 (2014) 1301465. http://dx.doi.org/10.1002/aenm.201301465.

[8] R. Nitsche, D.F. Sargent, P. Wild, Crystal growth of quaternary $1_{2} 246_{4}$ chalcogenides by iodine vapor transport, J. Cryst. Growth. 1 (1967) 52-53. http://dx.doi.org/10.1016/0022-0248(67)90009-7.

[9] K. Tanaka, Y. Miyamoto, H. Uchiki, K. Nakazawa, H. Araki, Donor-acceptor pair recombination luminescence from Cu2ZnSnS4 bulk single crystals, Phys. Stat. Sol. (A). 203 (2006) 2891-2896. http://dx.doi.org/10.102/pssa.200669545.

[10] A. Nagaoka, K. Yoshino, H. Taniguchi, T. Taniyama, H. Miyake, Growth of Cu2ZnSnS4 Single Crystal by Traveling Heater Method, Jpn. J. Appl. Phys. 50 (2011) 128001. http://dx.doi.org/10.1143/JJAP.50.128001.

[11] A. Nagaoka, K. Yoshino, H. Taniguchi, T. Taniyama, H. Miyake, Preparation of Cu2ZnSnS4 single crystals from Sn solutions, J. Cryst. Growth. 341 (2012) 38-41. http://dx.doi.org/101016/jjcrysgro201112046. 
[12] S. Levcenko, E.V. Tezlevan, E. Arushanov, S. Schorr, T. Unold, Free-to-bound recombination in near stoichiometric Cu2ZnSnS4 single crystals, Phys. Rev. B. 86 (2012) 045206.

http://dx.doi.org/10.1103/PhysRevB.86.045206.

[13] A. Nagaoka, K. Yoshino, H. Taniguchi, T. Taniyama, H. Miyake, Growth of Cu2ZnSnSe4 single crystals from Sn solutions, J. Cryst. Growth. 354 (2012) 147 - 151.

http://dx.doi.org/10.1016/j.jcrysgro.2012.05.030.

[14] S. Levcenco, D. Dumcenco, Y.P. Wang, Y.S. Huang, C.H. Ho, E. Arushanov, et al., Influence of anionic substitution on the electrolyte electroreflectance study of band edge transitions in single crystal Cu2ZnSn(SxSe1-x)4 solid solutions, Opt. Mater. 34 (2012) 1362-1365.

http://dx.doi.org/10.1016/j.optmat.2012.02.028.

[15] D. Dumcenco, Y. Huang, The vibrational properties study of kesterite Cu2ZnSnS4 single crystals by using polarization dependent Raman spectroscopy, Opt. Mater. 35 (2013) 419-425.

http://dx.doi.org/10.1016/j.optmat.2012.09.031.

[16] A. Nagaoka, H. Miyake, T. Taniyama, K. Kakimoto, K. Yoshino, Correlation between intrinsic defects and electrical properties in the high-quality Cu2ZnSnS4 single crystal, App. Phys. Lett. 103 (2013) 112107. http://dx.doi.org/10.1063/1.4821279.

[17] D. Nam, J. Kim, J. Lee, A. Nagaoka, K. Yoshino, W. Cha, et al., Polarized Raman spectroscopy of Cupoor and Zn-rich single-crystal Cu2ZnSnSe4, App. Phys. Lett. 105 (2014) 173903.

http://dx.doi.org/10.1063/1.4900560.

[18] D. Sandip, K.C. Mandal, Growth and characterization of kesterite Cu2ZnSn(SxSe1-x)4 crystals for photovoltaic applications, Mater. Res. Bull. 57 (2014) 135-139.

http://dx.doi.org/10.1016/j.materresbull.2014.04.073.

[19] S. Podsiadlo, M. Bialoglowski, G. Matyszczak, P. Marek, W. Gebicki, R. Bacewicz, et al., Synthesis of Bulk Kesterite - A Prospective Photovoltaic Material, Eur. J. Inorg. Chem. 2014 (2014) 4730-4733. http://dx.doi.org/10.1002/ejic.201402392.

[20] A. Nagaoka, K. Yoshino, K. Aoyagi, T. Minemoto, Y. Nose, T. Taniyama, et al., Thermo-physical properties of Cu2ZnSnS4 single crystal, J. Cryst. Growth. 393 (2014) 167 - 170. http://dx.doi.org/10.1016/j.jcrysgro.2013.11.077.

[21] M. Dimitrievska, A. Fairbrother, A. Pérez-Rodríguez, E. Saucedo, V. Izquierdo-Roca, Raman scattering crystalline assessment of polycrystalline Cu2ZnSnS4 thin films for sustainable photovoltaic technologies: Phonon confinement model, Acta Mater. 70 (2014) 272-280. http://dx.doi.org/10.1016/j.actamat.2014.02.035.

[22] D.M. Bishop, B.E. McCandless, R. Haight, D.B. Mitzi, R.W. Birkmire, Fabrication and Electronic Properties of CZTSe Single Crystals, IEEE J. Photovolt. 5 (2015) 390-394. http://dx.doi.org/10.1109/JPHOTOV.2014.2363552. 
[23] D. Colombara, A. Crossay, D. Regesch, C. Broussillou, T.G. de Monsabert, P. Grand, et al., Prediction of photovoltaic $p-n$ device short circuit current by photoelectrochemical analysis of $p$-type CIGSe films, Electrochem. Comm. 48 (2014) 99 - 102. http://dx.doi.org/10.1016/j.elecom.2014.08.026.

[24] J.B. Sambur, T. Novet, B.A. Parkinson, Multiple Exciton Collection in a Sensitized Photovoltaic System, Science. 330 (2010) 63-66. http://dx.doi.org/10.1126/science.1191462.

[25] S. Ushiroda, N. Ruzycki, Y. Lu, M.T. Spitler, B.A. Parkinson, Dye Sensitization of the Anatase (101) Crystal Surface by a Series of Dicarboxylated Thiacyanine Dyes, J. Am. Chem. Soc. 127 (2005) 5158-5168. http://dx.doi.org/10.1021/ja044001t.

[26] K. Tanaka, Y. Miyamoto, H. Uchiki, K. Nakazawa, H. Araki, Donor-acceptor pair recombination luminescence from Cu2ZnSnS4 bulk single crystals, Phys. Stat. Sol. (A). 203 (2006) 2891-2896. http://dx.doi.org/10.102/pssa.200669545.

[27] S.G. Patel, Light Intensity Variation Studies of MoS2/Electrolyte Interface, Cryst. Res. Technol. 27 (1992) 285-292. http://dx.doi.org/10.1002/crat.2170270223.

[28] T. Nakazawa, K. Takamizawa, K. Ito, High efficiency indium oxide/cadmium telluride solar cells, App. Phys. Lett. 50 (1987) 279. http://dx.doi.org/10.1063/1.98224.

[29] H. Du, C.H. Champness, I. Shih, Results on monocrystalline CulnSe2 solar cells, Thin Solid Films. 480481 (2005) 37-41. http://dx.doi.org/10.1016/j.tsf.2004.11.057.

[30] I. Visoly-Fisher, S. Cohen, A. Ruzin, D. Cahen, How Polycrystalline Devices Can Outperform Single-Crystal Ones: Thin Film CdTe/CdS Solar Cells, Adv. Mater. 16 (2004) 879-883. http://dx.doi.org/10.1002/adma.200306624.

[31] J.B. Li, V. Chawla, B.M. Clemens, Investigating the Role of Grain Boundaries in CZTS and CZTSSe Thin Film Solar Cells with Scanning Probe Microscopy, Advanced Materials. 24 (2012) 720-723. http://dx.doi.org/10.1002/adma.201103470.

[32] S. Schorr, The crystal structure of kesterite type compounds: A neutron and X-ray diffraction study, Sol. Energy Mater. Sol. Cells. 95 (2011) 1482-1488. http://dx.doi.org/10.1016/j.solmat.2011.01.002.

[33] D. Berg, M. Arasimowicz, R. Djemour, L. Gütay, S. Siebentritt, S. Schorr, et al., Discrimination and detection limits of secondary phases in Cu2ZnSnS4 using X-ray diffraction and Raman spectroscopy, Thin Solid Films. 569 (2014) 113-123. http://dx.doi.org/10.1016/j.tsf.2014.08.028.

[34] M. Mousel, A. Redinger, R. Djemour, M. Arasimowicz, N. Valle, P. Dale, et al., $\mathrm{HCl}$ and Br2-MeOH etching of Cu2ZnSnSe4 polycrystalline absorbers, Thin Solid Films. 535 (2013) 83 - 87.

http://dx.doi.org/10.1016/j.tsf.2012.12.095.

[35] A.D. Collord, H. Xin, H.W. Hillhouse, Combinatorial Exploration of the Effects of Intrinsic and Extrinsic Defects in Cu2ZnSn(S,Se)4, IEEE J. Photovolt. 5 (2015) 288-298.

http://dx.doi.org/10.1109/JPHOTOV.2014.2361053. 
[36] M. Erkan, V. Chawla, I. Repins, M. Scarpulla, Interplay between surface preparation and device performance in CZTSSe solar cells: Effects of $\mathrm{KCN}$ and $\mathrm{NH} 4 \mathrm{OH}$ etching, Solar Energy Materials And Solar Cells. 136 (2015) 78-85. http://dx.doi.org/10.1016/j.solmat.2015.01.006

[37] T. Tanaka, T. Sueishi, K. Saito, Q. Guo, M. Nishio, K.M. Yu, et al., Existence and removal of Cu2Se second phase in coevaporated Cu2ZnSnSe4 thin films, Journal Of Applied Physics. 111 (2012). http://dx.doi.org/10.1063/1.3691964.

[38] A. Fairbrother, E. García-Hemme, V. Izquierdo-Roca, X. Fontané, F.A. Pulgarín-Agudelo, O. VigilGalán, et al., Development of a Selective Chemical Etch To Improve the Conversion Efficiency of Zn-Rich Cu2ZnSnS4 Solar Cells, Journal Of The American Chemical Society. 134 (2012) 8018-8021. http://dx.doi.org/10.1021/ja301373e.

[39] M. Mousel, T. Schwarz, R. Djemour, T.P. Weiss, J. Sendler, J.C. Malaquias, et al., Cu-Rich Precursors Improve Kesterite Solar Cells, Advanced Energy Materials. 4 (2014) 1300543. http://dx.doi.org/10.1002/aenm.201300543.

40] K. Timmo, M. Altosaar, J. Raudoja, M. Grossberg, M. Danilson, O. Volobujeva, et al., Chemical etching of Cu2ZnSn(S,Se)4 monograin powder, in: Photovoltaic Specialists Conference (PVSC), 2010 35th IEEE, 2010: pp. 001982-001985. http://dx.doi.org/10.1109/PVSC.2010.5616411

[41] M. Bär, B.-A. Schubert, B. Marsen, S. Krause, S. Pookpanratana, T. Unold, et al., Impact of KCN etching on the chemical and electronic surface structure of Cu2ZnSnS4 thin-film solar cell absorbers, Applied Physics Letters. 99 (2011). http://dx.doi.org/10.1063/1.3650717.

[42] B. Schubert, B. Marsen, S. Cinque, T. Unold, R. Klenk, S. Schorr, et al., Cu2ZnSnS4 thin film solar cells by fast coevaporation, Prog. Photovolt: Res. Appl. 19 (2011) 93-96. http://dx.doi.org/10.1002/pip.976.

[43] K.K. Kam, B.A. Parkinson, Detailed Photocurrent Spectroscopy of the Semiconducting Group VI Transition Metal Dichaicogenldes, J. Phys. Chem. 86 (1982) 463-467. http://dx.doi.org/10.1021/j100393a010

[44] S. Chen, X.G. Gong, A. Walsh, S. Wei, Crystal and electronic band structure of Cu2ZnSnX4 X=S and Se photovoltaic absorbers: First-principles insights, App. Phys. Lett. 94 (2009) 041903-4. http://dx.doi.org/10.1063/1.3074499.

[45] C. Persson, Electronic and optical properties of Cu2ZnSnS4 and Cu2ZnSnSe4, J. App. Phys. 107 (2010) 053710. http://dx.doi.org/10.1063/1.3318468. 


\section{Figure 1}

Photograph of Kesterite crystal prior to cutting (a) and optical microscope image of the Large Kesterite crystal piece (b)

a

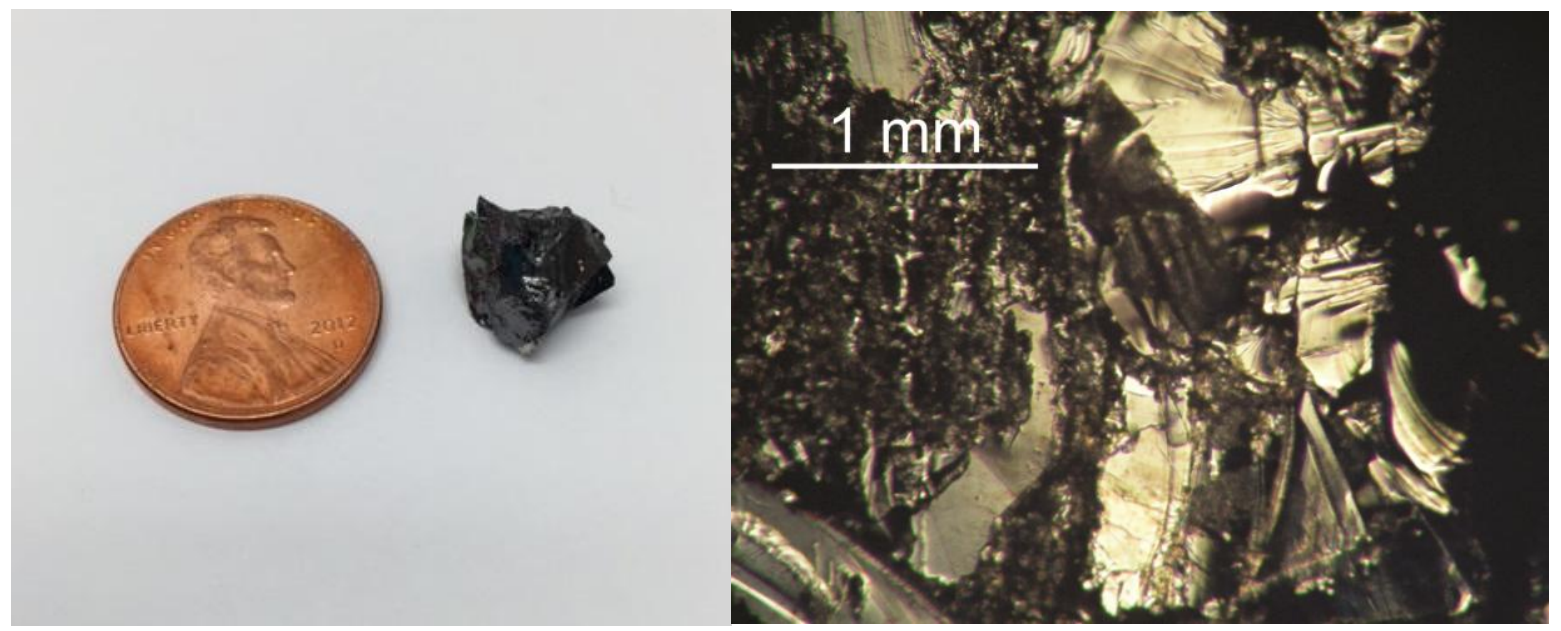

\section{Figure 2}

Scanning Electron Microscope images of Large (a) and Small Kesterite (b) pieces.

a

b

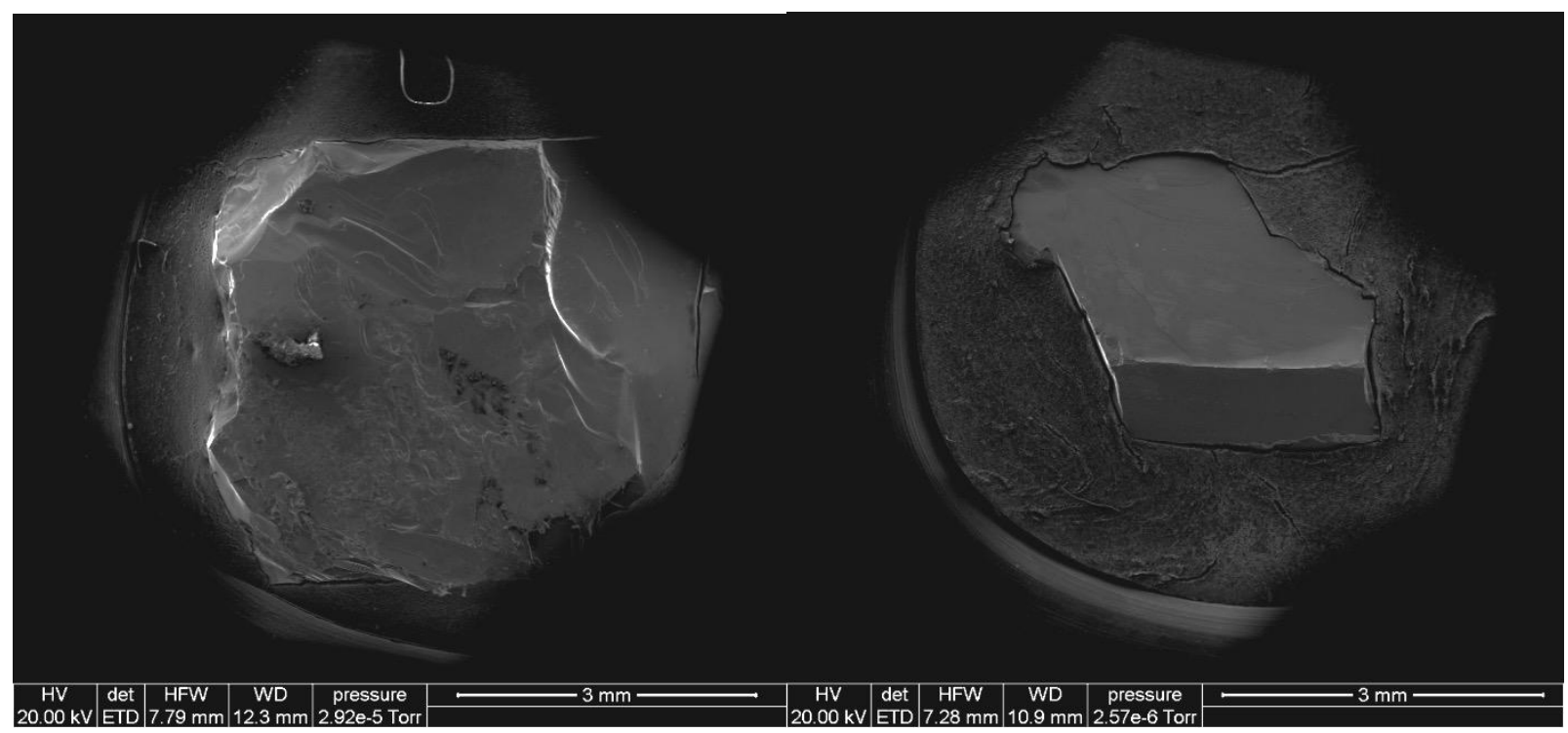




\section{$\underline{\text { Table } 1}$}

Summary of elemental analysis results from Energy Dispersive X-Ray Spectroscopy of Large Kesterite (5 areas), Small Kesterite ( 3 areas), and Post KCN etched (4 areas) samples. Standard deviation is a result of analyses of multiple points within an area (12 per area).

\begin{tabular}{|l|l|l|l|l|l|l|}
\hline Crystal/Area & \multicolumn{1}{|c|}{ S/metals } & Cu/Fe+Zn+Sn & \multicolumn{1}{|c|}{ Fe+Zn/Sn } & \multicolumn{1}{|c|}{ Fe/Zn } & Fe/Fe+Zn & \multicolumn{1}{c|}{ Cu/Fe+Zn } \\
\hline Large/1 & $1.211 \pm .013$ & $0.957 \pm .011$ & $.956 \pm .011$ & $.162 \pm .004$ & $.139 \pm .003$ & $1.96 \pm .03$ \\
\hline Large/2 & $1.101 \pm .004$ & $.988 \pm .008$ & $1.032 \pm .009$ & $.155 \pm .004$ & $.135 \pm .003$ & $1.95 \pm .02$ \\
\hline Large/3 & $1.190 \pm .014$ & $.958 \pm .012$ & $.974 \pm .012$ & $.167 \pm .004$ & $.143 \pm .004$ & $1.94 \pm .03$ \\
\hline Large/4 & $1.135 \pm .009$ & $.982 \pm .010$ & $1.007 \pm .016$ & $.169 \pm .005$ & $.145 \pm .004$ & $1.96 \pm .02$ \\
\hline Large/5 & $1.094 \pm .127$ & $.990 \pm .044$ & $1.051 \pm .114$ & $.166 \pm .008$ & $.142 \pm .006$ & $1.94 \pm .03$ \\
\hline Small/1 & $1.266 \pm .006$ & $.939 \pm .008$ & $.948 \pm .012$ & $.154 \pm .004$ & $.133 \pm .003$ & $1.93 \pm .02$ \\
\hline Small/2 & $1.270 \pm .007$ & $.942 \pm .008$ & $.943 \pm .011$ & $.156 \pm .005$ & $.135 \pm .004$ & $1.94 \pm .02$ \\
\hline Small/3 & $.849 \pm .005$ & $1.087 \pm .012$ & $1.276 \pm .018$ & $.141 \pm .003$ & $.123 \pm .003$ & $1.94 \pm .02$ \\
\hline & & & & & & \\
\hline PostKCN/1 & $1.073 \pm .020$ & $.999 \pm .017$ & $1.044 \pm .031$ & $.152 \pm .010$ & $.132 \pm .008$ & $1.957 \pm .054$ \\
\hline PostKCN/2 & $1.158 \pm .010$ & $.971 \pm .022$ & $.999 \pm .018$ & $.155 \pm .010$ & $.134 \pm .005$ & $1.942 \pm .050$ \\
\hline PostKCN/3 & $1.125 \pm .012$ & $.975 \pm .015$ & $1.007 \pm .022$ & $.153 \pm .008$ & $.133 \pm .006$ & $1.943 \pm .035$ \\
\hline PostKCN/4 & $1.096 \pm .010$ & $.993 \pm .018$ & $1.020 \pm .025$ & $.156 \pm .008$ & $.135 \pm .006$ & $1.968 \pm .053$ \\
\hline
\end{tabular}




\section{Figure 3}

Raman Spectra of synthetic CZTS single crystal (black), the Large Kesterite (red) and the Small Kesterite (blue) samples using a $532 \mathrm{~nm}$ laser excitation. Peaks at $288-291 \mathrm{~cm}^{-1}$ and $338-341 \mathrm{~cm}^{-1}$ match with reported CZTS stretches and single crystal CZTS. Shoulders at $355 \mathrm{~cm}^{-1}$ have been associated with the $\mathrm{Cu}_{2} \mathrm{SnS}_{3}$ (monoclinic) phase.

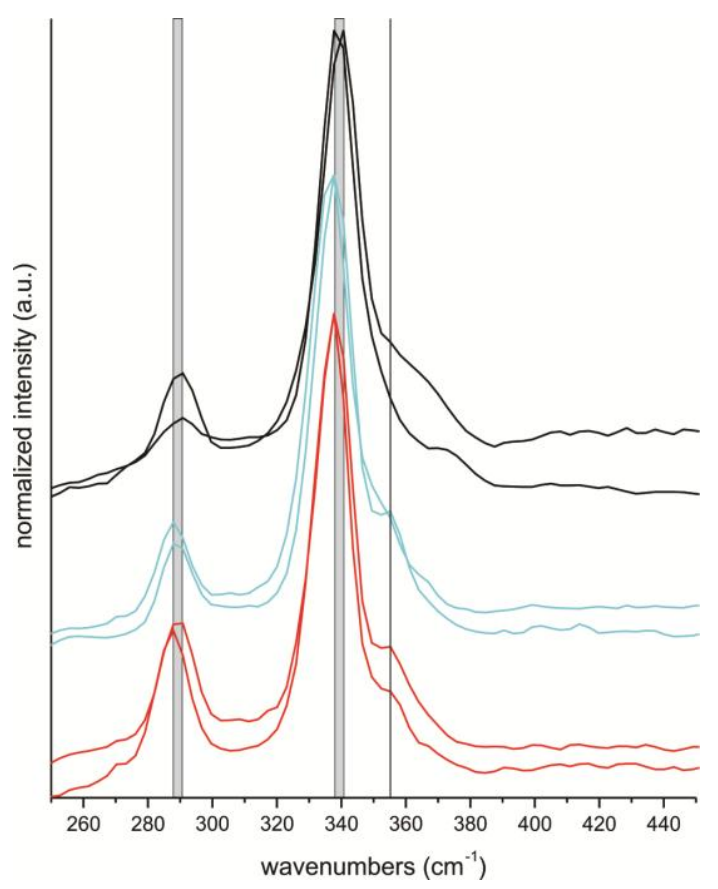




\section{Figure 4}

Chopped photocurrent voltammetry of the large kesterite piece (LK) and post KCN etched piece in contact with $10 \mathrm{mM}$ cobaltacinium hexafluorphosphate and $100 \mathrm{mM}$ tetrabutylammonium

hexafluorophosphate in acetonitrile solution while chopping a $40 \mathrm{~mW} 532 \mathrm{~nm}$ laser while illuminating different areas of crystals ( $25 \mathrm{mV} / \mathrm{s}$ scan rate).

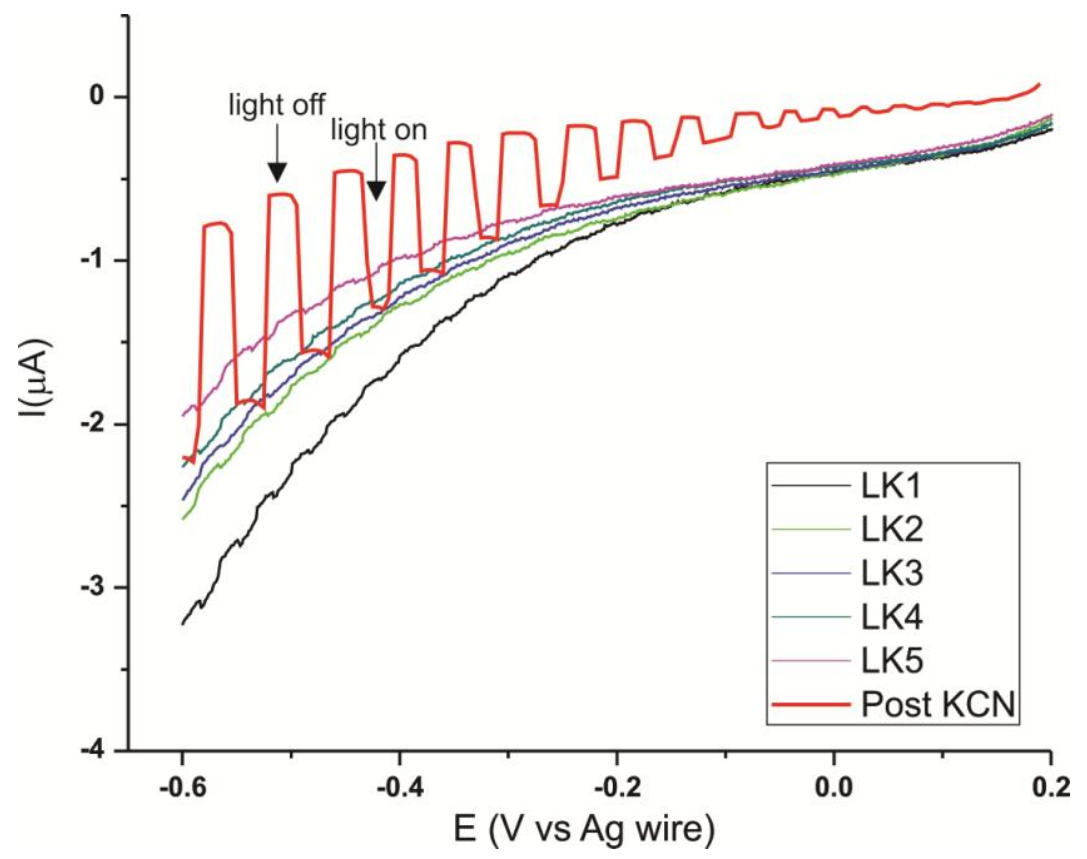




\section{Figure 5}

Incident Photon to Current Efficiency (IPCE) spectrum of the Small Kesterite piece (A) and post KCN piece $(B)$ in contact with $10 \mathrm{mM}$ cobaltacinium hexafluorphosphate $\left(E^{0}=-.755 \mathrm{~V}\right.$ vs $\mathrm{Ag}$ wire) and $100 \mathrm{mM}$ tetrabutylammonium hexafluorophosphate in acetonitrile solution at $-0.5 \mathrm{~V}$ vs $\mathrm{Ag}$ wire bias using a lockin amplifier with a chopping frequency of $17 \mathrm{~Hz}$.

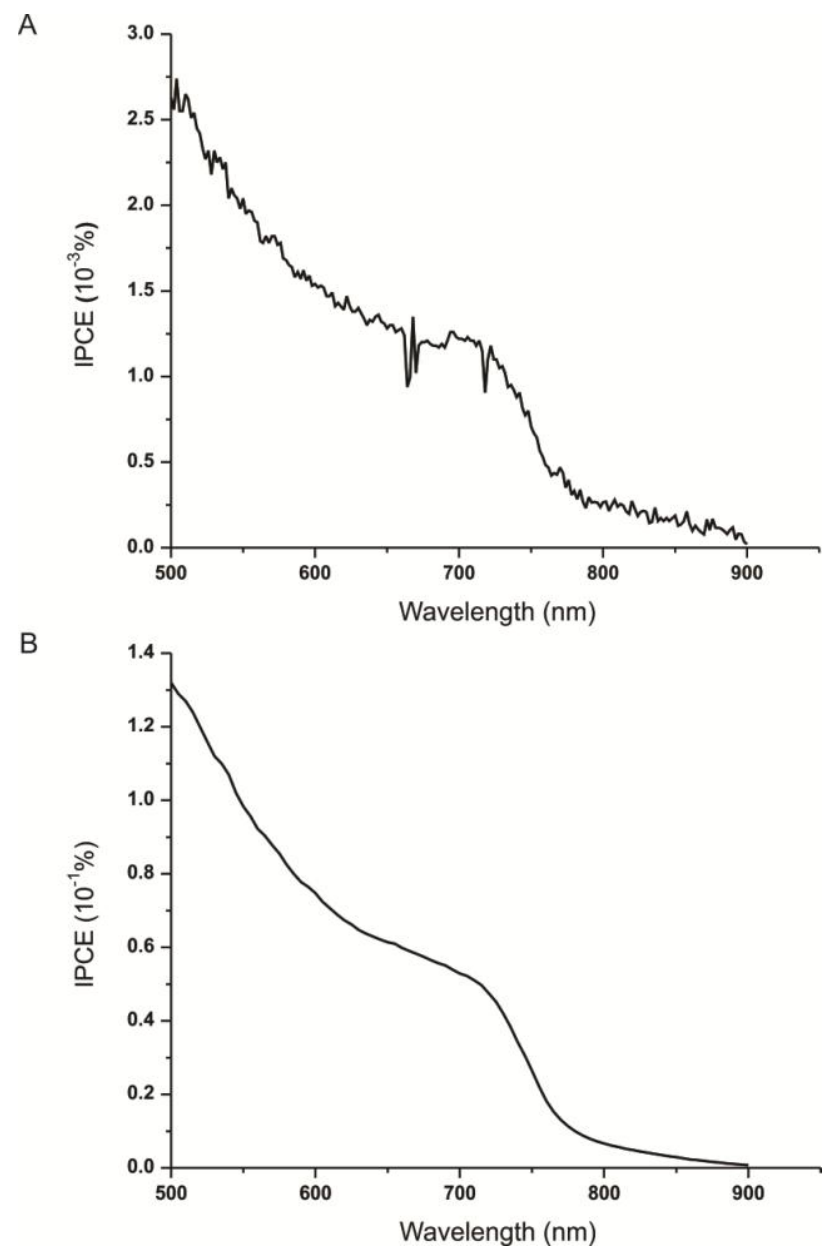




\section{Figure 6}

Determination of the bandgap of small kesterite piece (A) and post KCN piece (B) based on the assumption that it is a direct bandgap material.

A
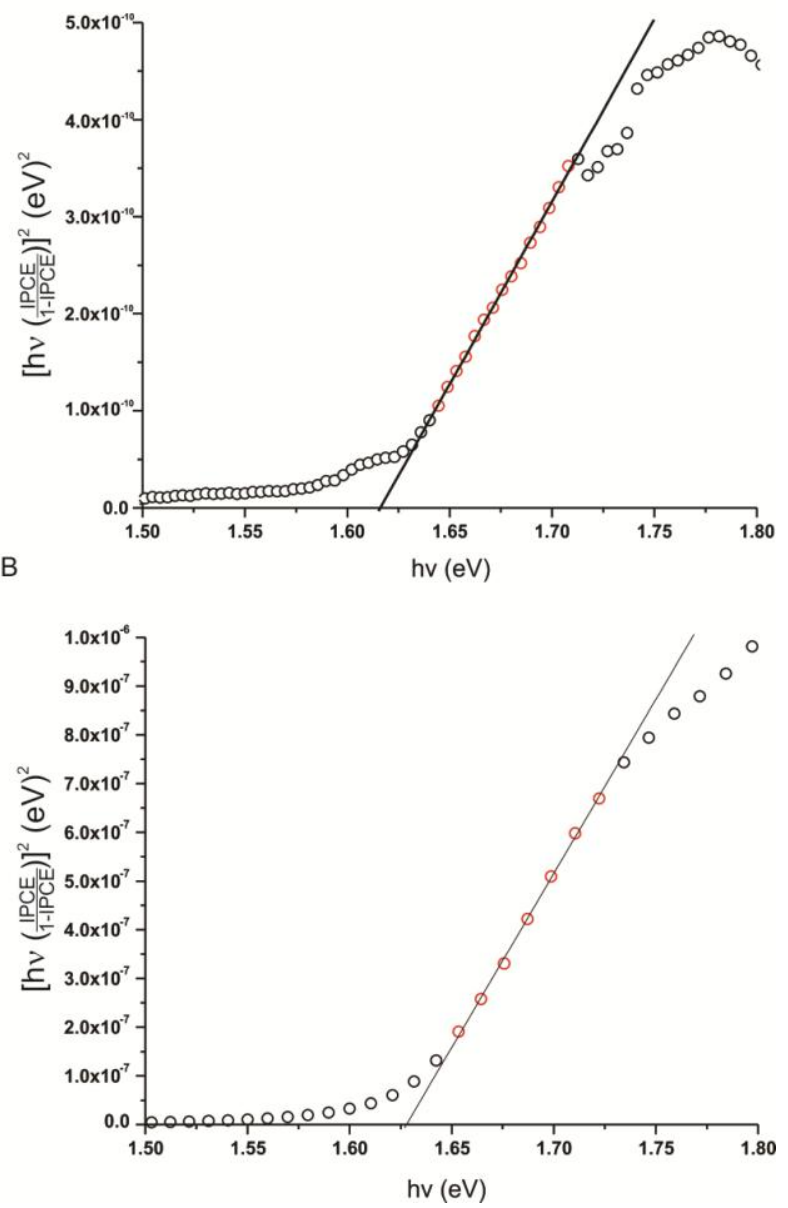


\section{Figure 7}

Mott-Schottky plots for negative to positive potential sweeps of pre (dark blue) and post (red) as well as positive to negative potential sweeps of pre (open light blue) and post (open pink) KCN etched crystals. The pre etching crystal acceptor densities were calculated to be $7.6-7.8 \mathrm{E} 18 \mathrm{~cm}^{-3}$, whereas the post etching densities were $6.3-8.8 \mathrm{E} 17 \mathrm{~cm}^{-3}$. The intercepts also significantly changed from $+2.1 \mathrm{~V}$ vs $\mathrm{Ag}$ wire to $+.5 \mathrm{~V}$ vs Ag wire.

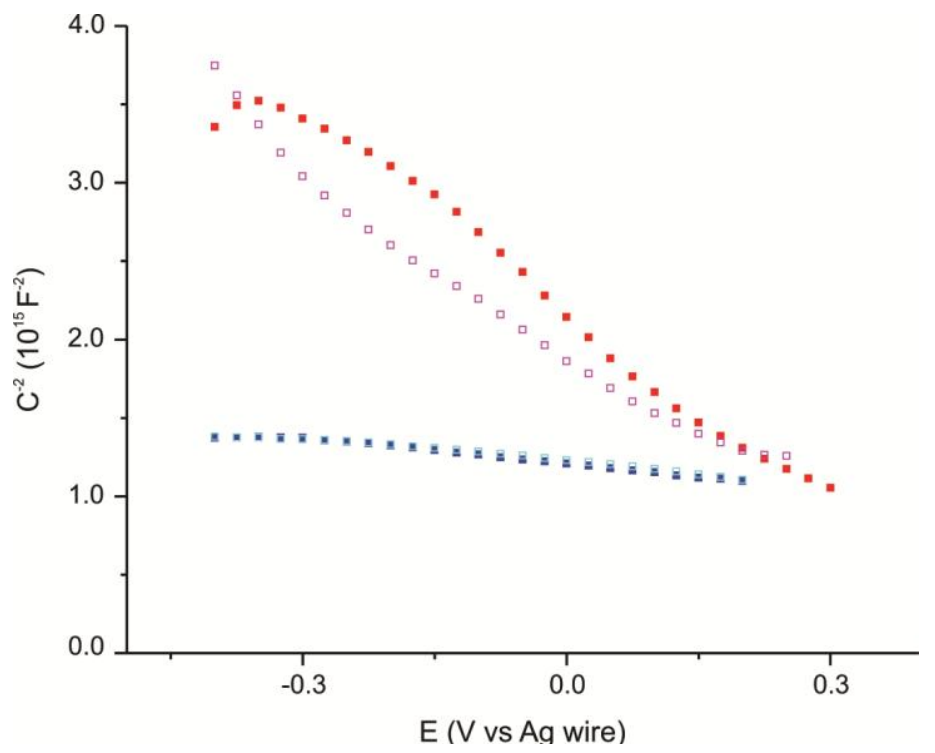

